\title{
REVIEW
}

Open Access

\section{Effectiveness and mechanisms of adipose- derived stem cell therapy in animal models of Parkinson's disease: a systematic review and meta-analysis}

Keya Li, Xinyue Li, Guiying Shi, Xuepei Lei, Yiying Huang, Lin Bai ${ }^{*}$ and Chuan Qin*

\begin{abstract}
Animal models provide an opportunity to assess the optimal treatment way and the underlying mechanisms of direct clinical application of adipose-derived stem cells (ADSCs). Previous studies have evaluated the effects of primitive and induced ADSCs in animal models of Parkinson's disease (PD). Here, eight databases were systematically searched for studies on the effects and in vivo changes caused by ADSC intervention. Quality assessment was conducted using a 10-item risk of bias tool. For the subsequent meta-analysis, study characteristics were extracted and effect sizes were computed. Ten out of 2324 published articles ( $n=169$ animals) were selected for further meta-analysis. After ADSC therapy, the rotation behavior (10 experiments, $n=156$ animals) and rotarod performance ( 3 experiments, $n=54$ animals) were improved ( $P<0.00001$ and $P=0.0003$, respectively). The rotation behavior test reflected functional recovery, which may be due to the neurogenesis from neuronally differentiated ADSCs, resulting in a higher pooled effect size of standard mean difference (SMD) $(-2.59 ; 95 \% \mathrm{Cl},-$ 3.57 to -1.61$)$ when compared to that of primitive cells $(-2.18 ; 95 \% \mathrm{Cl},-3.29$ to -1.07$)$. Stratified analyses by different time intervals indicated that ADSC intervention exhibited a long-term effect. Following the transplantation of ADSCs, tyrosine hydroxylase-positive neurons recovered in the lesion area with pooled SMD of $13.36[6.85,19.86]$. Transplantation of ADSCs is a therapeutic option that shows long-lasting effects in animal models of PD. The potential mechanisms of ADSCs involve neurogenesis and neuroprotective effects. The standardized induction of neural form of transplanted ADSCs can lead to a future application in clinical practice.
\end{abstract}

Keywords: Parkinson's disease, Adipose-derived stem cells, Animal model, Stem cell therapy, Meta-analysis, Neurogenesis, Neuroprotection

\footnotetext{
*Correspondence: bailin49@163.com; qinchuan@pumc.edu.cn

NHC Key Laboratory of Human Disease Comparative Medicine, Beijing Key Laboratory for Animal Models of Emerging and Reemerging Infectious Diseases, Institute of Laboratory Animal Science, Chinese Academy of Medical Sciences and Comparative Medicine Center, Peking Union Medical College, Beijing 100021, China
}

(c) The Author(s). 2021 Open Access This article is licensed under a Creative Commons Attribution 4.0 International License, which permits use, sharing, adaptation, distribution and reproduction in any medium or format, as long as you give appropriate credit to the original author(s) and the source, provide a link to the Creative Commons licence, and indicate if changes were made. The images or other third party material in this article are included in the article's Creative Commons licence, unless indicated otherwise in a credit line to the material. If material is not included in the article's Creative Commons licence and your intended use is not permitted by statutory regulation or exceeds the permitted use, you will need to obtain permission directly from the copyright holder. To view a copy of this licence, visit http://creativecommons.org/licenses/by/4.0/ The Creative Commons Public Domain Dedication waiver (http://creativecommons.org/publicdomain/zero/1.0/) applies to the data made available in this article, unless otherwise stated in a credit line to the data. 


\section{Introduction}

Parkinson's disease (PD) is the second most common progressive neurodegenerative disorder. It was initially described as the 'shaking palsy' by James Parkinson in 1877 [1]. Pathologically, PD is characterized by a prominent loss of midbrain dopamine (DA)-secreting neurons with the presence of $\alpha$-synuclein-containing Lewy bodies, which result in a series of clinical features [1]. The clinical symptoms of PD include non-motor and motor symptoms such as rigidity, bradykinesia, and essential resting tremor, which is distinct from the tremors caused by epilepsy, alcoholism, or stroke [2, 3]. It has been reported that male adults over 50 years of age are susceptible to PD [4]. With the increased aging population, disability and death from neurological disorders have been on the rise [5]. PD has now become the leading cause of disability worldwide. In 2016, it was reported that PD had caused 3,200,000 disability-adjusted of life years and more than 20,000 mortalities [4].

Current therapeutic options for PD are aimed at improving the motor symptomatology in PD patients using pharmacologic agents [6, 7]. However, DA agonists can cause side effects such as impulse control disorders, which has limited their long-term application [7]. Although medical treatment has been performed in PD patients since the early 1960s [1], the disease remains incurable so far. Even in early stages of PD, surgical techniques can only control and retard the progression of PD. Therefore, it is important to develop novel therapeutic strategies for the treatment of PD. Since the progression of $\mathrm{PD}$ involves $\mathrm{DA}$ neuron loss in the substantia nigra (SN), dopaminergic protection and cell replacement have been proposed as critical perspectives for curing this disease.

Mesenchymal stem cells (MSCs) are adult stem cells that have immunosuppressive functions and are less prone to tumorigenesis. Unlike embryonic or fetalderived cell transplantation, the transplantation of autologous adult stem cells is not hindered by ethical issues or safety limitations [6, 8]. Adipose-derived stem cells (ADSCs) are a primary source of MSCs. They are abundant and easy to be isolated through less invasive procedures compared to the bone marrow MSCs. They have a great proliferative potential, can be expanded through multiple passages in vitro with minimal senescence, and offer direct application in the field of tissue engineering [9-11]. They can also be selectively differentiated into endoderm and ectoderm cell lineages in vitro under appropriate conditions [12-15].

With these advantages, ADSCs have been evaluated for the treatment of different diseases. They have been intra-articularly administered for the treatment of osteoarthritis [16], percutaneously as well as endoscopically injected for the management of postoperative enterocutaneous fistula [17], and intracerebroventricularly injected in human brains for neurodegenerative diseases [18].

Animal models of PD are often established with 6hydroxydopamine (6-OHDA) [19-27], rotenone [28, 29], 1-methyl-4-phenyl-1,2,3,6-tetrahydropyridine (MPTP) $[30,31]$ and lipopolysaccharide [32]. The animal models have been used to study the therapeutic effects of ADSCs for PD, with varied transplantation forms and follow-up times.

In this review, we perform meta-analysis of preclinical studies to estimate the optimal transplantation route and therapeutic effects of ADSCs in PD animal models, and summarize the therapeutic mechanisms of ADSCs.

\section{Methods}

Search methods

Online search was performed in eight databases (PubMed, Embase, Web of Science, Scopus, CINAHL, Cochrane Library, Medline, ProQuest Dissertations and Theses) to identify studies on the effects and mechanisms of ADSC treatment in animal models of PD by the date of March 21, 2020. The PICO (population, interventions, comparators, and outcomes) strategy was used as a reminder of the scope of the review, defined by the types of population (participants), types of interventions (and comparisons), and the types of outcomes that are of interest [33]. The systematic search in PubMed is described in Supplementary file 1.

\section{Inclusion criteria}

The inclusion criteria are described in Table S1 using the PICO strategy. All the included articles should be in English and provide experimental data. Briefly, we selected peer-reviewed studies on the effects and in vivo changes caused by ADSC interventions in common models of PD. Experiments should have been prospectively controlled, and behavioral outcomes and in vivo data after transplantation should have been provided. Titles were evaluated for possible duplicates, type of article (not a review), type of research (animal studies), and theme fitted. Abstracts were reviewed for experimental PD models and ADSC intervention. Full-text papers were assessed for study design, treatment and control groups, and outcome measurements.

\section{Outcome measurements}

Studies reporting the following outcomes were selected: behavioral tests like rotation (turns/min) or rotarod (s) tests, and in vivo changes like DA neurons, protein expression after transplantation or positron emission tomography/magnetic resonance imaging. 


\section{Risk of bias of included studies}

Study quality and risk of bias were assessed by the SYRC LE's risk of bias (RoB) tool provided by the SYstematic Review Centre for Laboratory Animal Experimentation. This tool, based on the Cochrane Collaboration RoB Tool, aims to assess the methodological quality and has been adapted to aspects of bias that play a role in animal experiments [34]. This tool contains 10 items that are associated with 6 types of bias: selection bias, performance bias, detection bias, attrition bias, reporting bias, and other biases. The 10 items are organized into subitems in the form of questions with an answer of "Yes", "No" or "Unclear". "Yes" indicates a bias with low risk, "No" refers to a high risk of bias, while "Unclear" means that the risk of bias is unknown, usually because that the item was not reported. The assessment was performed by two reviewers independently, and any controversy was resolved by discussion. An overview of this RoB tool entry is shown in Table S2.

\section{Data extraction and management}

The following information was extracted from each article: author information, publication year, source of ADSCs, animal species, lesion models, number of animals per study arm group, administration route, ADSC doses, number of days between lesioning and treatment, follow-up duration, and the outcome data, including rotation behavior, rotarod test results, and tyrosine hydroxylase $(\mathrm{TH})$-positive neurons. Data in text, tables and graphs were extracted. Studies that mentioned both primitive ADSCs and neural-induction ADSCs were considered as two independent experiments. They were discerned into subgroups according to the type of intervention: Primitive ADSCs and neural induction form of ADSCs, and according to the valid duration: follow-up time $\leq 4$ weeks; and follow-up time $>4$ weeks. We only extracted behavioral data at the final time point of serial behavioral testing. Where the outcomes were reported graphically but not as numerical data in the text, values of mean and standard deviation (SD) or standard error of the mean (SEM) were extracted from the images by two authors (KYL and XYL) using WebPlotDigitizer 4.2. Readings by them were averaged and SEM was converted to SD for data analysis.

\section{Statistical analysis}

Treatment effects are expressed as standard mean difference (SMD) for continuous variables, for comparison of ADSC versus control groups. We applied the DerSimonian and Laird random-effects model for anticipated heterogeneity of the extracted data [35]. SMD was calculated with the Hedges statistical method and is displayed with 95\% confidence interval (95\% CI) in forest plots. Heterogeneity among studies was assessed using the $I^{2}$ statistics, and the statistical significance of the pooled effect size among studies was determined by the z-test. To determine whether our findings were highly influenced by any single study, sensitivity analysis was performed by iteratively removing one study at a time. Moreover, potential publication bias was evaluated by Egger's and Begg's tests and displayed in funnel plots, in which a publication bias was considered when $P<0.05$. All analyses were performed with Review Manager 5.3 for Mac (Copenhagen: The Nordic Cochrane Centre, The Cochrane Collaboration) and Stata/SE 15.0 for Mac (StataCorp LP, College Station, TX).

\section{Results}

\section{Characteristics of the included studies}

A total of 2,324 studies were identified from the systematic search, among which 10 studies [19, 20, 22-25, 27, $28,30,31$ ] met the inclusion criteria after full-text assessment (Fig. 1, Table 1 and Table S3).

The 10 studies involved 169 animals (control group, $n$ $=74$; treatment group, $n=95)$. The most frequently used PD model was the 6-OHDA model (7 studies), followed by the MPTP (2 studies) and rotenone (1 study) models. Rats were the most preferred animals for experimentation (Table S4).

The effectiveness of ADSC intervention included decreased rotation numbers and longer stay on the rotarod (expressed in SMD). Histologically, TH-positive neurons in 3 experiments from 3 studies were scored in uniform scoring scales. Therefore, meta-analyses were performed on these outcomes.

\section{Assessment of the risk of bias}

The risk-of-bias summary of each study based on the SYRCLE's RoB tool is shown in Table S5, and the main observation was "unclear" (Fig. 2). As for the selection bias (Q1-Q3), animals were randomly assigned in only one study (10\%; Q1); baseline similarities were more often in these articles (60\%; Q2), whereas no studies documented the information regarding allocation concealment (Q3). Performance bias could not be established (Q4 and Q5). None of the articles reported random housing, although it is unlikely that outcomes were influenced by lack of random housing (Q4). There was no blinding of caregivers and/or investigators (Q5). With respect to detection bias (Q6 and Q7), none of the studies randomly selected animals for outcome assessment (Q6). In addition, the outcome assessor in one study was not blinded (10\%; Q7). However, the outcome was not likely to be impacted by lack of blinding (Q7). Incomplete outcome data were addressed in one study (10\%; Q8), and a low risk was identified in 3 studies. With respect to the reporting bias (Q9) and other bias (Q10), high risks were identified in 4 studies $(40 \%)$. The 


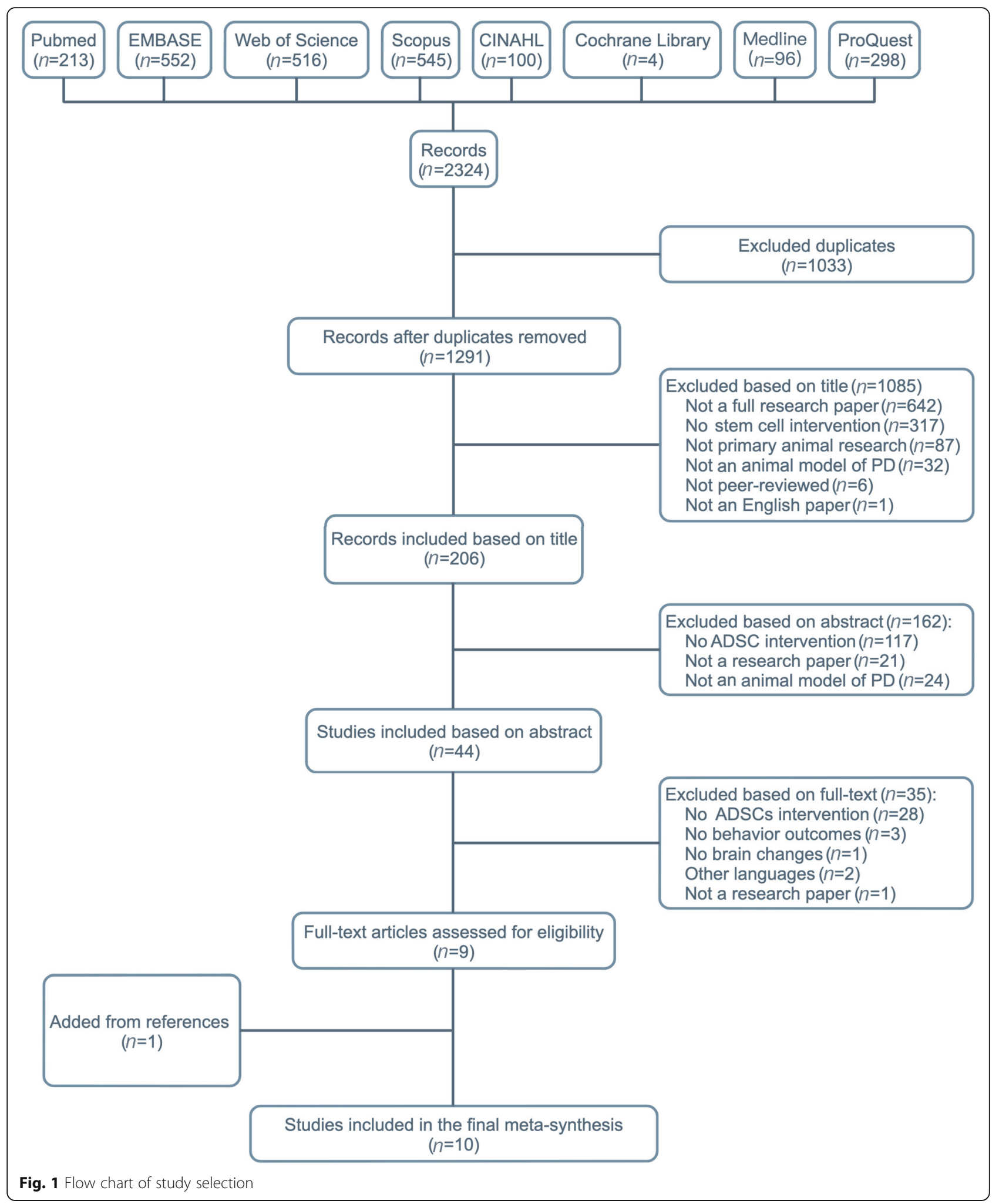


Table 1 List of all 10 studies that met the inclusion criteria based on full-text assessment

\begin{tabular}{|c|c|c|c|c|c|c|c|}
\hline $\begin{array}{l}\text { Author } \\
\text { (year) }\end{array}$ & $\begin{array}{l}\text { Type of } \\
\text { intervention }\end{array}$ & Model & $\begin{array}{l}\text { Species/ } \\
\text { Strains }\end{array}$ & $\begin{array}{l}\text { Route of } \\
\text { administration }\end{array}$ & $\begin{array}{l}\text { Doses per } \\
\text { animal }\end{array}$ & $\begin{array}{l}\text { Follow- } \\
\text { up time }\end{array}$ & Outcome parameters \\
\hline $\begin{array}{l}\text { McCoy } \\
(2008)[19]\end{array}$ & $\begin{array}{l}\text { Neural } \\
\text { induction }\end{array}$ & 6-OHDA & $\begin{array}{l}\text { Rats/ } \\
\text { Sprague- } \\
\text { Dawley }\end{array}$ & Intrastriatal & $4 \times 10^{4}$ & 4 weeks & $\begin{array}{l}\text { Rotation (turns } / 20 \mathrm{~min} \text { ) } \\
\text { Number of } \mathrm{TH}^{+} \text {neurons in SNpc and striatum } \\
\text { Microglial burden in SNpc (IOD) }\end{array}$ \\
\hline $\begin{array}{l}\text { Zhou (2013) } \\
\text { [30] }\end{array}$ & $\begin{array}{l}\text { Neural } \\
\text { induction }\end{array}$ & $\begin{array}{l}\text { MPTP } \\
\text { (hemi) }\end{array}$ & $\begin{array}{l}\text { Monkeys/ } \\
\text { Rhesus }\end{array}$ & Intrastriatal & $6 \times 10^{6}$ & 4 months & $\begin{array}{l}\text { UPDRS (scores) } \\
\text { Rotation (turns/min) } \\
\text { Percentage of } \mathrm{TH}^{+} \text {neurons in the substantia nigra }\end{array}$ \\
\hline $\begin{array}{l}\text { Park (2014) } \\
{[20]}\end{array}$ & Original & 6-OHDA & $\begin{array}{l}\text { Rats/ } \\
\text { Sprague- } \\
\text { Dawley }\end{array}$ & $\begin{array}{l}\text { Cisterna magna } \\
\text { injection }\end{array}$ & $2 \times 10^{6}$ & 6 weeks & $\begin{array}{l}\text { Rotation (turns } / 50 \mathrm{~min} \text { ) } \\
\text { Relative neuronal protein expression of midbrain } \\
\text { tissues }\end{array}$ \\
\hline $\begin{array}{l}\text { Berg (2015) } \\
{[24]}\end{array}$ & Original & 6-OHDA & Rats/Wistar & Intranigral & $3 \times 10^{5}$ & 3 weeks & $\begin{array}{l}\text { 8-arm radial maze (times) } \\
\text { Rotation (turns/min) } \\
\text { Number of newly generated cells in the adult DG } \\
\text { Nigral mRNA levels of GDNF, BDNF and GFAP } \\
\text { Microglia number in the transplantation area }\end{array}$ \\
\hline $\begin{array}{l}\text { Choi (2015) } \\
\text { [23] }\end{array}$ & Original & 6-OHDA & Mice/C57BL6 & Intravenous & $1 \times 10^{6}$ & 6 weeks & $\begin{array}{l}\text { Rotation (turns/30 min) } \\
\text { Rotarod (s) } \\
\text { Number of TH Neurons in the SN } \\
\text { PET imaging analysis of dopamine D2 receptor in } \\
\text { the striatum (binding potential) } \\
\text { The population of damaged mitochondria (\%) } \\
\text { Mitochondrial complex I activity (\%) }\end{array}$ \\
\hline $\begin{array}{l}\text { Schwerk } \\
\text { (2015) [22] }\end{array}$ & Original & 6-OHDA & Rats/Wistar & Intranigral & $3 \times 10^{5}$ & 6 months & $\begin{array}{l}\text { Rotation (turns/min) } \\
8 \text {-arm radial maze (times) } \\
\text { Percentage of } \mathrm{TH}^{+} \text {neurons in the SN (\%) } \\
\text { Neurogenesis of subventricular and hippocampal } \\
\text { cells (cell number) } \\
\text { EPO, IL-10, IL-4, and IL-2 levels (pg/ml) }\end{array}$ \\
\hline $\begin{array}{l}\text { Takahashi } \\
\text { (2017) [25] }\end{array}$ & $\begin{array}{l}\text { Neural } \\
\text { induction }\end{array}$ & 6-OHDA & Rats/Wistar & $\begin{array}{l}\text { Ipsilateral MFB } \\
\text { injection }\end{array}$ & $4 \times 10^{5}$ & 4 weeks & Rotation (turns/min) \\
\hline $\begin{array}{l}\text { Chi (2018) } \\
\text { [31] }\end{array}$ & Original & MPTP & Mice/C57BL6 & Intrastriatal & $1 \times 10^{6}$ & 3 weeks & $\begin{array}{l}\text { Beam walking (s) } \\
\text { Rotarod (s) } \\
\text { Locomotor activity } \\
\text { Comparable TH quantity of the SN (\%) }\end{array}$ \\
\hline $\begin{array}{l}\text { Meligy } \\
(2019)[28]\end{array}$ & Original & Rotenone & Rats/Wistar & Intracardiac & $1 \times 10^{6}$ & 2 weeks & $\begin{array}{l}\text { Rotarod (s) } \\
\text { Activity cage (counts/5 min) } \\
\text { Pole test (s) } \\
\text { Pale and dark neurons in SNc (cell number) } \\
\mathrm{TH}^{+} \text {cells in the SNc (cells/mm²) } \\
\text { Blood levels of angiopoietin-2 (ng/ml) and dopa- } \\
\text { mine (pg/ml) } \\
\text { GFAP and Nestin mRNA gene expression }\end{array}$ \\
\hline $\begin{array}{l}\text { Moayeri } \\
(2020)[27]\end{array}$ & Original & $6-\mathrm{HD}$ & $\begin{array}{l}\text { Rats/ } \\
\text { Sprague- } \\
\text { Dawley }\end{array}$ & $\begin{array}{l}\text { Ipsilateral MFB } \\
\text { injection }\end{array}$ & $3 \times 10^{5}$ & 6 weeks & $\begin{array}{l}\text { Rotation (turns } / 1 \mathrm{~h} \text { ) } \\
\text { Nissl-stained cells in the SNc }\end{array}$ \\
\hline
\end{tabular}

Abbreviations: $T H$ Tyrosine hydroxylase, $S N C$ substantia nigra compacta, $D G$ dentate gyrus, $M F B$ medial forebrain bundle, $B P n$-butylidenephthalid

high risks in item 10 were exclusively due to a lack of specified SD or SEM.

\section{Therapeutic effects of ADSCs}

There was an average of $0.32 \%$ difference in the rotation and rotarod test data extracted by the two authors.

\section{Rotation behavior}

Ten experiments from 8 studies involving 165 animals tested the effects of ADSCs on rotation behavior, and showed the same direction of effect. The pooled effect size of SMD for ADSC efficacy in PD treatment was -2.24 (95\% CI, -3.12 to $-1.36, \mathrm{z}=4.99, P<0.00001$ ), which demonstrated substantial and significant attenuation of apomorphine/amphetamine-induced rotational behavior by ADSC treatment (Fig. 3a). Both primitive ADSCs (7 experiments) and neural-induction ADSCs (3 experiments) contributed to behavioral improvement $(P$ $<0.000$ 01) (Fig. 3b). The neural-induction ADSCs exhibited a more synergic effect size (SMD, $-2.59 ; 95 \% \mathrm{CI}$, -3.57 to -1.61 ) than the primitive ones (SMD, -2.18 ; $95 \% \mathrm{CI},-3.29$ to -1.07$)$. 

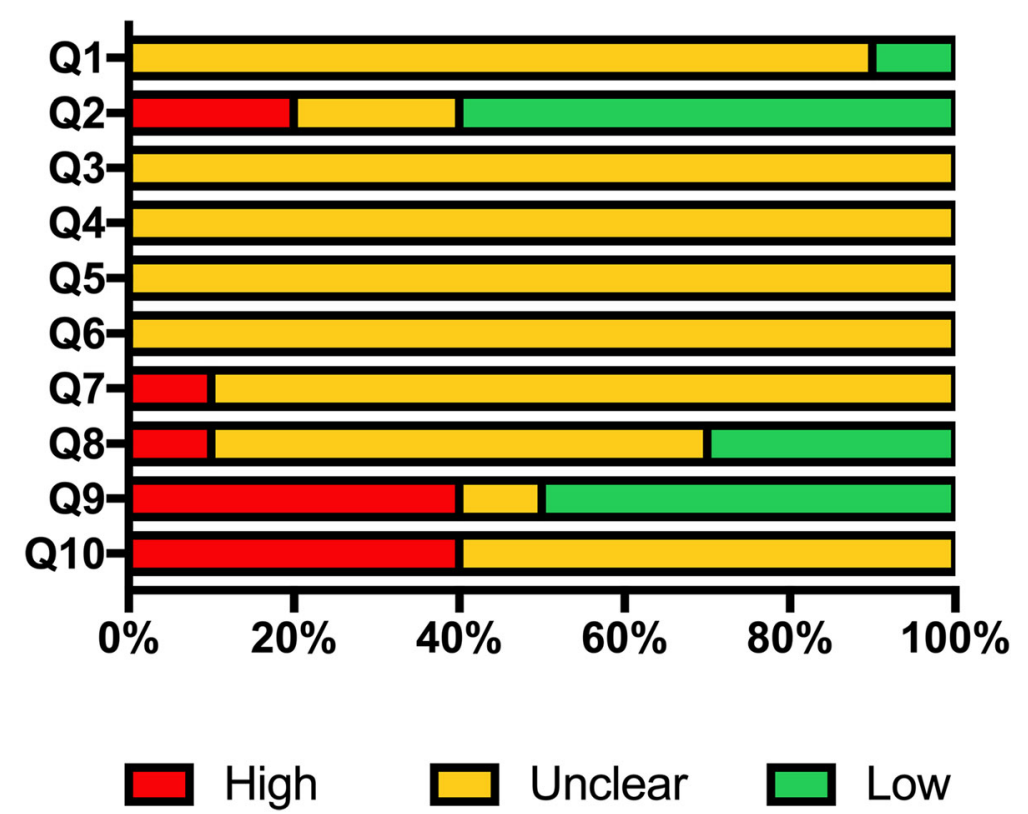

Fig. 2 Quality assessment of the 10 studies. Q1. Was the allocation sequence adequately generated and applied? Q2. Were the groups similar at baseline or were they adjusted for confounders in the analysis? Q3. Was the allocation to the different groups adequately concealed during the experiment? Q4. Were the animals randomly housed during the experiment? Q5. Were the caregivers and/or investigators blinded from knowledge which intervention each animal received during the experiment? Q6. Were animals selected at random for outcome assessment? Q7. Was the outcome assessor blinded? Q8. Were incomplete outcome data adequately addressed? Q9. Are reports of the study free of selective outcome reporting? Q10. Was the study apparently free of other problems that could result in high risk of bias?

\section{Rotarod test}

Three experimental studies (including 54 animals) evaluated the effects of ADSCs on rotarod test performance. The results showed that ADSC intervention could significantly prolong the latency to fall during the rotarod test of PD models (overall pooled SMD, 1.75; 95\% CI, 0.80-2.71; $\mathrm{z}=3.60 ; P=0.000$ 3) (Fig. 3c).

\section{Subgroup analysis}

Since the follow-up time may impact the intervention effects, the studies were divided into two groups according to the follow-up time. In this analysis, the only one study with a monkey model was excluded. Analysis of data at the final point of follow-up showed that the improvement of rotation behavior weakened over time (Fig. 4a). The overall-effect $\mathrm{z}$ value of the $\leq 4$ weeks subgroup was $7.65(P<0.00001)$ and the pooled SMD was -2.60 (95\% CI, -3.27 to -1.94 ), while the overall-effect $\mathrm{z}$ value and pooled SMD of the $>4$ weeks subgroup were 2.75 $(P=0.006)$ and -2.00 (95\% CI, -3.42 to -0.58$)$, respectively. In fact, in the studies with follow-up time over 4 weeks, the rotation behavior of animals had been improved before the final time point. Considering the between-group differences, we included data at shorter follow-up but with most improved effects from the $>4$ weeks subgroup to the $\leq 4$ weeks subgroup (Fig. 4b). The overall-effect $\mathrm{z}$-value of the $\leq 4$ weeks subgroup was $4.48(P<0.00001)$ while the pooled SMD with 95\% CI was -1.74[-2.50, -0.98]. These results suggest that ADSC intervention exerts a long-term effect.

\section{Mechanisms of the therapeutic effect Neurogenesis}

All of the 10 studies have mentioned DA neuron survival after ADSC intervention in PD models. Seven studies $[19,22-24,27,28,31]$ presented quantitative analysis of TH-positive neurons in the brain, which consistently showed that the DA neurons recovered after ADSC transplantation. Three of them [19, 23, 27] evaluated $\mathrm{TH}^{+}$neurons in the $\mathrm{SN}$, so the numbers of $\mathrm{TH}^{+}$neurons were combined for meta-analysis. Results showed that the overall pooled SMD was 13.36 (95\% CI, 6.85-19.86) and the $z$-value was $4.02(P<0.00001)$, favoring the use of ADSCs over controls for the outcome of $\mathrm{TH}^{+}$neuron numbers within the lesioned side (Fig. 5). Heterogeneity was not significant $\left(I^{2}=38 \%\right)$ [36].

Therapeutic ADSCs have also been shown to increase striatum $\mathrm{TH}^{+}$neurons [19], hippocampal dentate gyrus cells [24], and neurogenesis in the subventricular region with long-term increased expression of proliferating cell nuclear antigen in the ipsilateral midbrain, a marker for cell proliferation [22]. Six months after transplantation, there were significantly more BrdU+ cells in the 


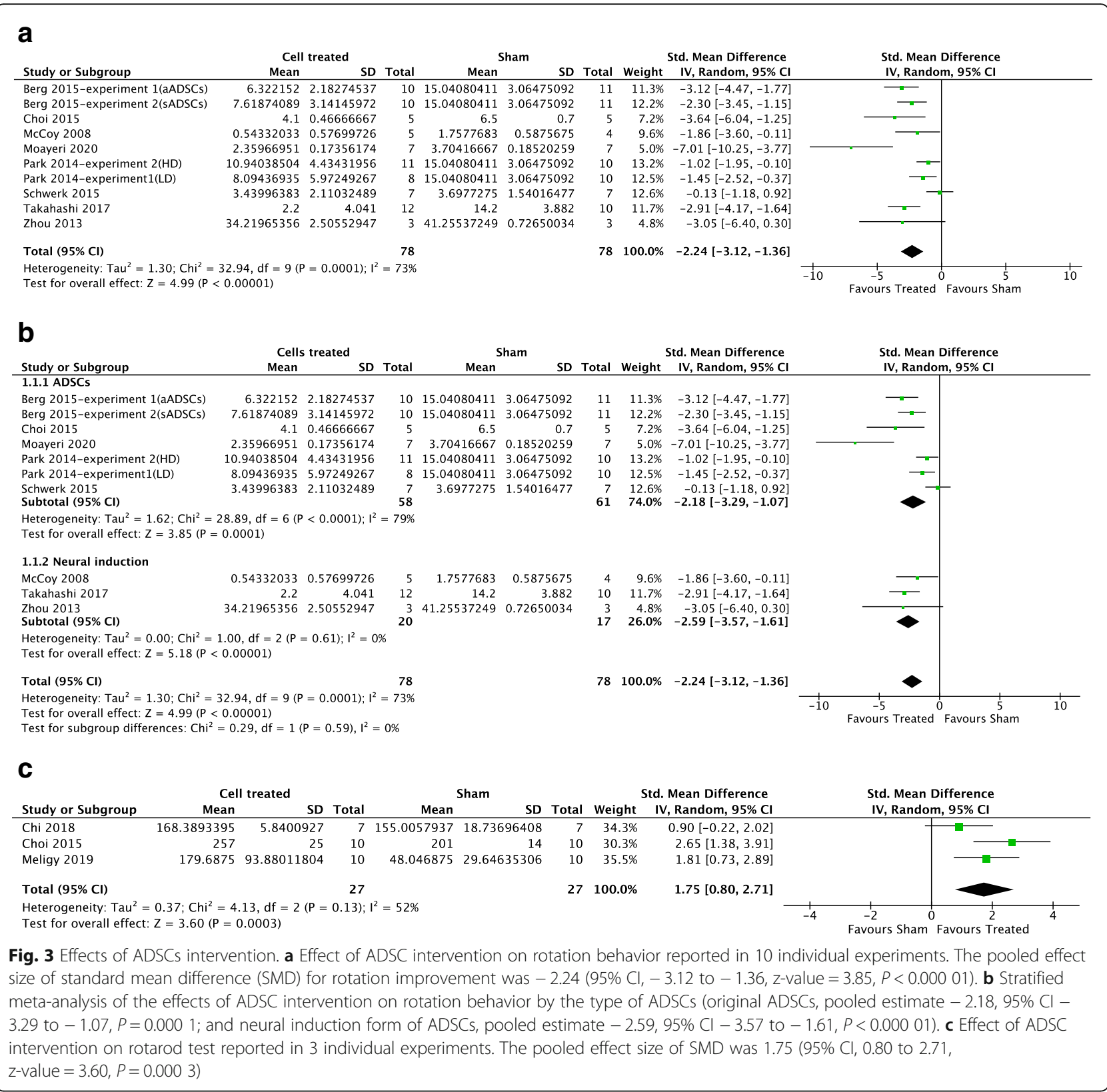

subgranular zone of the hippocampus when compared to the 6-OHDA model with control treatment [22]. Park JB et al. have documented that the PI3K/Akt pathway is involved in neuronal growth promotion by ADSCs cultured at high cell density [20].

\section{Neuroprotection}

In addition to the region-specific neurogenesis, primitive ADSCs can generate a broad range of neuroprotective effects.

McCoy has reported that microglial activation markers are decreased in the $\mathrm{SN}$ after intrastriatal injection of ADSCs, indicating a reduction in microglial density [19].
Erythropoietin, which plays antiapoptotic, antioxidant and anti-inflammatory roles in neurons [37, 38], has been found to be increased after transplantation [22].

Neurotrophic factors affect neuronal functions. They have the potential to protect DA neurons from degeneration and promote regeneration of the nigrostriatal DA system. Accumulating evidence has shown increased expression of brain-derived neurotrophic factor (BDNF) after ADSC transplantation in vitro and in vivo. The induction of interferons (IFNs) by ADSCs promotes the synthesis of BDNF through the IFN- $\beta$ signaling [20]. Moreover, ADSCs have been found to produce nerve growth factor, glial-derived neurotrophic factor [20, 22, 


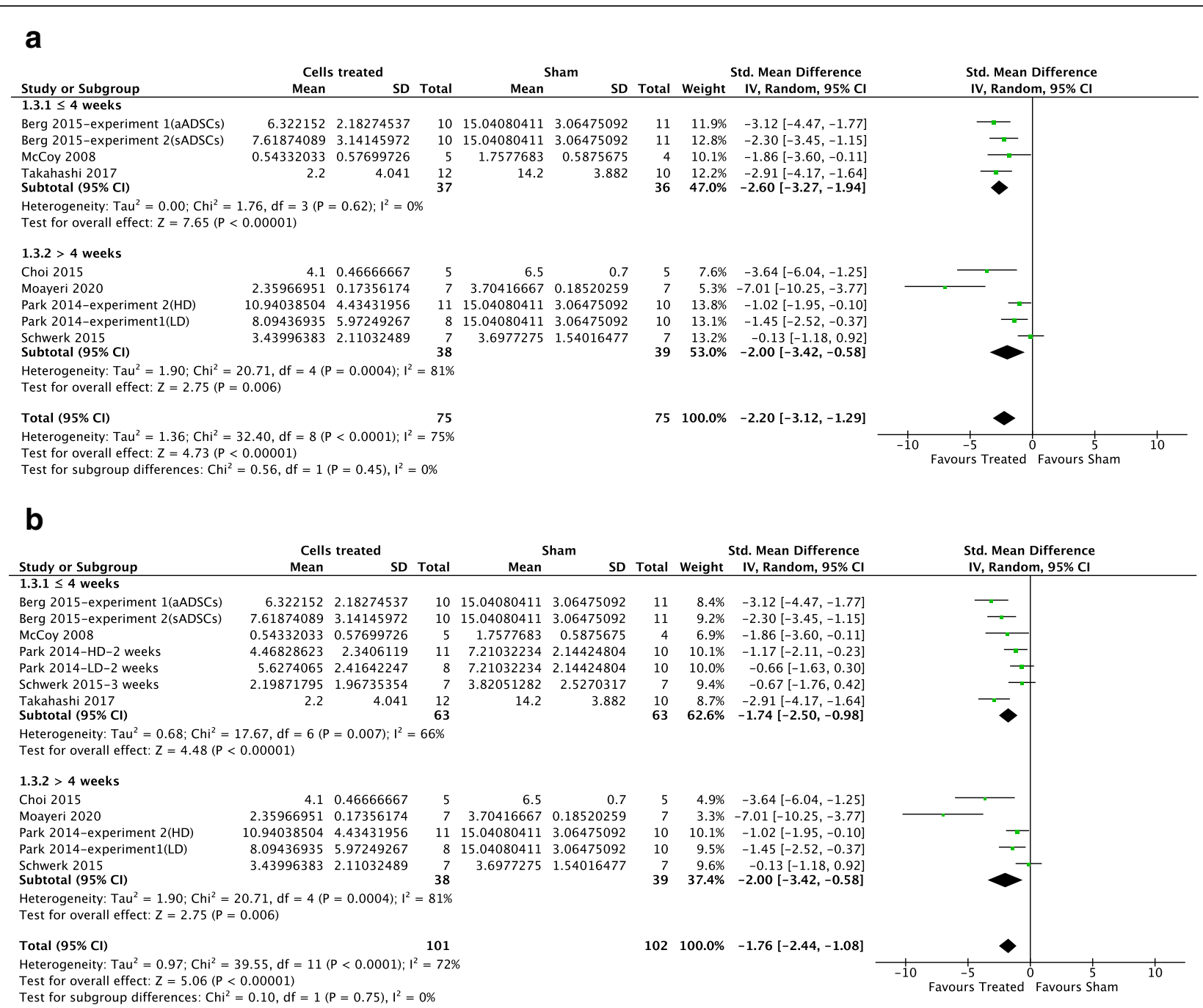

Fig. 4 Subgroup analyses by ADSC intervention period. a Effect of ADSC intervention period on rodent rotation behavior reported in 9 individual experiments. The pooled effect size of SMD for the subgroup of recording time point $\leq 4$ weeks was $-2.60(95 \% \mathrm{Cl},-3.27$ to -1.94 , z-value $=$ $7.65, P<0.000$ 01). b Data at shorter follow-up but with most improved effects from the $>4$ weeks subgroup were added to the $\leq 4$ weeks subgroup. The pooled effect size of SMD was $-1.74(95 \% \mathrm{Cl},-2.50$ to $-0.98, z$-value $=4.48, P<0.00001)$. The pooled effect size of SMD for rotation improvement at follow-up time over 4 weeks was $-2.00(95 \% \mathrm{Cl},-3.42$ to -0.58 , $z$-value $=2.75, P=0.006)$

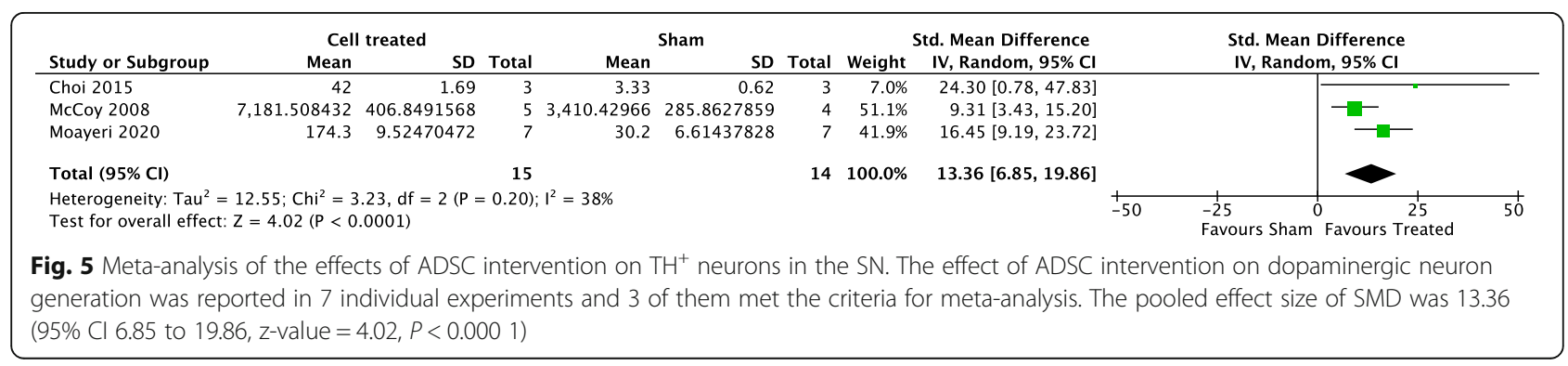


24], vascular endothelial growth factor, von Willebrand factor, basic fibroblast growth factor and insulin-like growth factor-1. These findings suggest the role of ADSCs in the induction of angiogenesis [20,28].

In addition, ADSCs express high levels of interleukin 10 (IL-10), IL-2 and IL-4, and restore mitochondrial dysfunction as well as the mitochondrial complex I activity, which is known to be inhibited by 6-OHDA [23].

In summary, therapeutic ADSCs exert their neuroprotective effects through neuroinflammation attenuation, immunoregulation, secretion of neurotropic and growth factors, recovery of dysfunctional mitochondria, and microenvironmental protection.

\section{Sensitivity}

Sensitivity analysis is used to detect whether the pooled results are still stable for their potential impact. We performed a leave-one-out sensitivity analysis by iteratively removing one study at a time and recalculating the pooled effect size of the remaining studies. For rotation behavior, rotarod test result and TH-positive neurons, the pooled effect was stable, indicating that the metaanalysis results were not driven by any single study.

\section{Publication bias}

The funnel plots for rotation behavior (Fig. 6a) and THpositive neurons (Fig. 6c) were asymmetric according to the Egger's and Begg's tests (Supplementary file 2). The funnel plot for rotarod was symmetric and $P>0.05$ was obtained from both Egger's and Begg's tests (Fig. 6b). These findings implied the possibility of publication bias on rotation behavior, rotarod test and $\mathrm{TH}^{+}$neurons in these studies.

\section{Discussion}

The key pathology of PD includes the loss of A9 nigral neurons that provide dopaminergic innervation to the striatum [39] and the presence of $\alpha$-synuclein-containing Lewy bodies in the brain [40]. Continuous loss of nigral DA neurons and the non-physiologic mode of drug delivery make stem cell therapy a promising strategy to alter the progression of this disease [41].

Autologous ADSCs circumvent ethical concerns and appear to be a suitable candidate of PD therapy [42]. This type of cells, which was first reported in 2001, is one of the most convenient and preferable types of stem cells [43]. ADSCs have been used in contexts of spinal cord injury-induced neuroinflammation [44], vascular remodeling [45], osteoarthritis [46], breast cancer [47], coronavirus disease 2019 [48], and neurodegenerative disorders [49-51].

As innovative preclinical assessment tools, neurotoxin-based PD animal models, which induce substantia nigra pars compacta dopaminergic neuronal

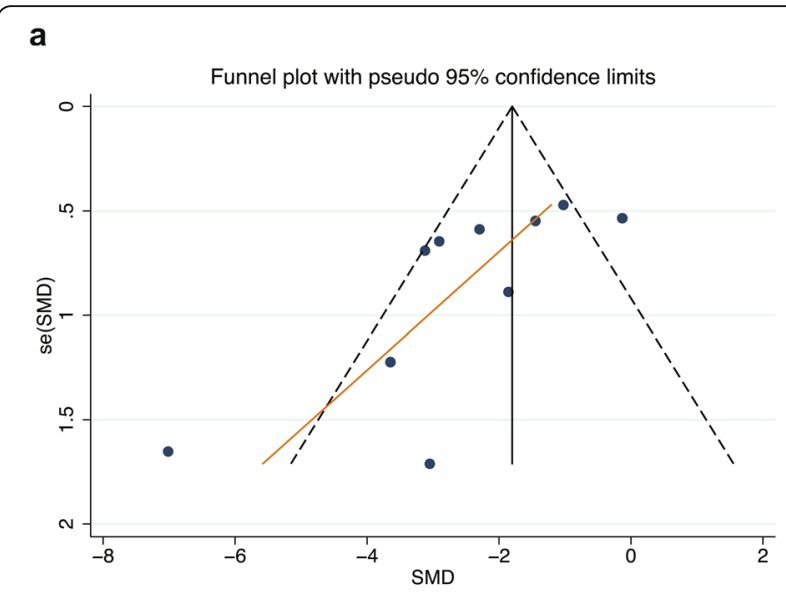

b

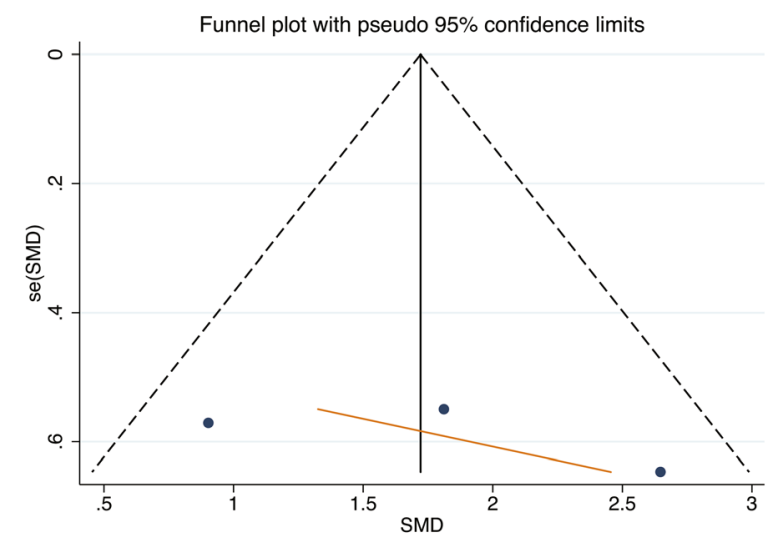

C

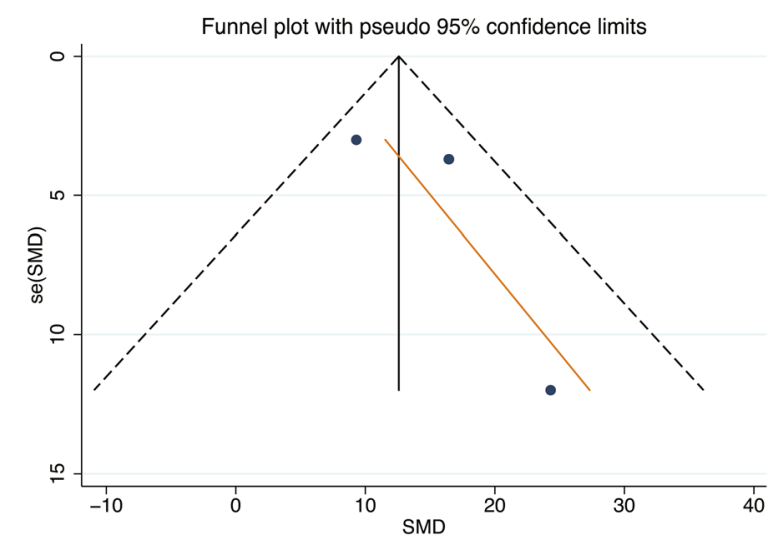

Fig. 6 Funnel plot for the effect size of ADSC therapy. a Effect size of ADSC therapy on rotation behavior. $\mathbf{b}$ Effect size of ADSC therapy on rotarod test result. $\mathbf{c}$ Effect size of ADSC therapy on the number of TH-positive neurons. Dots represent individual studies. The solid vertical line represents the pooled effect size. The dashed diagonal lines represent pseudo-95\% confidence limits around the pooled effect size for each standard error on the vertical axis. The diagonal solid line represents the fitted line between the treatment effect and its standard error for each study using Egger's test 
death, can be used to assess therapeutic effects on PD symptoms and side effects associated with DAreplacement therapies $[52,53]$. In this review, the included studies from 8 databases all used neurotoxinbased PD animal models, predominately the rodent 6OHDA model, the first and classic animal model of PD [54]. All studies have shown the same direction of effect of ADSC treatment, suggesting that ADSCs are useful cell sources for treating PD. To evaluate the optimal forms of ADSCs, the experiments reporting rotation behavior were divided into two groups: those using primitive ADSCs and those using neural induction form of ADSCs. The neural-induction ADSCs were found to more effectively improve outcomes compared to the primitive ADSCs, suggesting that ADSCs, especially the neural-induction ADSCs, are potential therapeutic options for cell replacement therapy of PD. This finding is consistent with previous studies in which stem cell therapies for PD tend to graft cells which are trans-differentiated into DA neurons as a direct supplement, in order to help reconstruct the nigrostriatal pathway [55-57]. Therefore, the ADSC-derived DA neurons provide an approach for PD treatment [42]. Due to the vulnerability of ADSCs after neural induction, intracerebral injection is the best route of administration [30]. Chi et al. have also documented that intracerebral injection of ADSCs could be applied to maximize the potential for recovery [31].

Then, we evaluated whether the follow-up time would influence the efficacy of ADSC treatment on rotation behavior, and investigated it as a source of heterogeneity in the data analysis. Subgroup analysis indicated significant ADSC treatment efficacy at either length of follow-up, suggesting that this therapy had a long-term effect. The heterogeneity of rotation data may be due to the route of administration, which varied among studies.

So what are the mechanisms underlying the functions of ADSCs? Based on these studies, the mechanisms involve neurogenesis and neuroprotection. DA neurons in the SN were increased after ADSC transplantation in all of the 10 studies, with quantification being done in seven studies. As for the neural-induction form of ADSCs, trans-differentiation and neurogenesis may be the main mechanisms of action. After transplantation of therapeutic ADSCs, the microenvironment is altered and neurotrophic factors are up-regulated, which provide a supplementary mechanism and nutritional niche in vivo $[19,25,30]$.

Several studies have also reported that ADSCs do not adopt DA neuron fates in vivo $[19,24]$, and primitive ADSCs have more neuroprotective effects than the differentiated cell types.

\section{Conclusions}

In conclusion, ADSC therapy is a promising regenerative therapeutic option for PD. The potential mechanisms underlying the effectiveness of ADSC therapy involve neurogenesis and neuroprotection. These findings imply that the successful application of ADSCs in clinical practice for PD relies on the neuronal induction form of ADSCs. However, larger studies are needed to confirm this conclusion.

\section{Abbreviations \\ PD: Parkinson's disease; DA: Dopamine; SN: Substantia nigra; MSCs: Mesenchymal stem cells; ADSCs: Adipose-derived stem cells; 6 - OHDA: 6-hydroxydopamine; MPTP: 1-methyl-4-phenyl-1,2,3,6 tetrahydropyridine; TH: Tyrosine hydroxylase; BDNF: Brain-derived neurotrophic factor; IFN: Interferon}

\section{Supplementary Information}

The online version contains supplementary material available at https://doi. org/10.1186/s40035-021-00238-1.

Additional file 1: Search strategy in Pubmed.

Additional file 2: Table S1. Inclusion criteria for experimental studies. Table S2. SYRCLE's tool for assessing risk of bias. Table S3. List of the 10 studies that met the inclusion criteria based on full-text assessment. Table S4. Summary of study characteristics of the 10 studies that were included in the meta-analysis. Table S5. Risk of bias assessment for each included study

Additional file 3: Egger's test and Begg's test of publication bias.

\section{Acknowledgements}

The author wish to acknowledge Kewei Wang (M.D., Ph.D., University of Illinois College of Medicine, USA) for writing assistance.

Authors' contributions

$\mathrm{KYL}, \mathrm{XYL}$ and $\mathrm{YYH}$ collected the data. KYL, GYS and XPL performed the analysis and wrote the manuscript. LB and CQ designed and supervised the project. All the authors read and approved the manuscript.

\section{Funding}

The authors acknowledge the financial support from the Research Fund for Doctor Innovation of Peking Union Medical College (2019-1001-14), Natural Science Foundation of Beijing Municipality (5171001), and CAMS Innovation Fund for Medical Sciences (2019-12M-1-006), and Natural Science Foundation of Beijing Municipality (5202024).

Availability of data and materials

All relevant data are within the paper and the online Supplementary files.

\section{Declarations}

Ethics approval and consent to participate

Not applicable.

Consent for publication

Not applicable.

Competing interests

None declared.

Received: 15 January 2021 Accepted: 13 April 2021

Published online: 29 April 2021

References

1. Barnett R. Parkinson's disease. Lancet. 2016;387(10015):217. 
2. Kalia LV, Lang AE. Evolving basic, pathological and clinical concepts in PD. Nat Rev Neurol. 2016;12(2):65-6.

3. Tolosa E, Wenning G, Poewe W. The diagnosis of Parkinson's disease. Lancet Neurol. 2006;5(1):75-86.

4. Dorsey ER, Elbaz A, Nichols E, Abd-Allah F, Abdelalim A, Adsuar J, et al. Global, regional, and national burden of Parkinson's disease, 1990-2016: a systematic analysis for the global burden of disease study. Lancet Neurol. 2018;17(11):939-53.

5. Group GBDNDC. Global, regional, and national burden of neurological disorders during 1990-2015: a systematic analysis for the global burden of disease study 2015. Lancet Neurol. 2017;16(11):877-97.

6. Pires AO, Teixeira FG, Mendes-Pinheiro B, Serra SC, Sousa N, Salgado AJ. Old and new challenges in Parkinson's disease therapeutics. Prog Neurobiol. 2017;156:69-89.

7. de Bie RMA, Clarke CE, Espay AJ, Fox SH, Lang AE. Initiation of pharmacological therapy in Parkinson's disease: when, why, and how. Lancet Neurol. 2020;19(5):452-61.

8. Glavaski-Joksimovic A, Bohn MC. Mesenchymal stem cells and neuroregeneration in Parkinson's disease. Exp Neurol. 2013;247:25-38.

9. Schaffler A, Buchler C. Concise review: adipose tissue-derived stromal cells-basic and clinical implications for novel cell-based therapies. Stem Cells. 2007;25(4):818-27.

10. Tabatabaei Qomi R, Sheykhhasan M. Adipose-derived stromal cell in regenerative medicine: a review. World J Stem Cells. 2017;9(8):107-17.

11. Huang Q, Zou Y, Arno MC, Chen S, Wang T, Gao J, et al. Hydrogel scaffolds for differentiation of adipose-derived stem cells. Chem Soc Rev. 2017;46(20): 6255-75.

12. Xie S, Lu F, Han J, Tao K, Wang H, Simental A, et al. Efficient generation of functional Schwann cells from adipose-derived stem cells in defined conditions. Cell Cycle. 2017;16(9):841-51.

13. Wystrychowski W, Patlolla B, Zhuge Y, Neofytou E, Robbins RC, Beygui RE. Multipotency and cardiomyogenic potential of human adipose-derived stem cells from epicardium, pericardium, and omentum. Stem Cell Res Ther. 2016;7(1):84

14. Qin Y, Zhou C, Wang N, Yang H, Gao WQ. Conversion of adipose tissuederived mesenchymal stem cells to neural stem cell-like cells by a single transcription factor, Sox2. Cell Reprogram. 2015;17(3):221-6.

15. García-Honduvilla N, Cifuentes A, Ortega MA, Delgado A, González S, Bujan $J$, et al. High sensitivity of human adipose stem cells to differentiate into myofibroblasts in the presence of egg extract. Stem Cells Int. 2017;2017: 9142493.

16. Fodor PB, Paulseth SG. Adipose derived stromal cell (adsc) injections for pain management of osteoarthritis in the human knee joint. Aesthet Surg J. 2016;36(2):229-36.

17. Mizushima T, Takahashi H, Takeyama H, Naito A, Haraguchi N, Uemura M, et al. A clinical trial of autologous adipose-derived regenerative cell transplantation for a postoperative enterocutaneous fistula. Surg Today. 2015;46(7):835-42.

18. Duma C, Kopyov O, Kopyov A, Berman M, Lander E, Elam M, et al. Human intracerebroventricular (ICV) injection of autologous, nonengineered, adipose-derived stromal vascular fraction (ADSVF) for neurodegenerative disorders: results of a 3-year phase 1 study of 113 injections in 31 patients. Mol Biol Rep. 2019;46(5):5257-72.

19. McCoy MK, Martinez TN, Ruhn KA, Wrage PC, Keefer EW, Bottennan BR, et al. Autologous transplants of adipose-derived adult stromal (ADAS) cells afford dopaminergic neuroprotection in a model of Parkinson's disease. Exp Neurol. 2008;210(1):14-29.

20. Park JB, Lee JS, Cho BP, Rhee KJ, Baik SK, Kim J, et al. Adipose tissue-derived mesenchymal stem cells cultured at high cell density express brain-derived neurotrophic factor and exert neuroprotective effects in a 6hydroxydopamine rat model of Parkinson's disease. Genes Genomics. 2014; 37(2):213-21.

21. Schwerk A, Altschueler J, Roch M, Gossen M, Winter C, Berg J, et al. Human adipose-derived mesenchymal stromal cells increase endogenous neurogenesis in the rat subventricular zone acutely after 6hydroxydopamine lesioning. Cytotherapy. 2015;17(2):199-214.

22. Schwerk A, Altschuler J, Roch M, Gossen M, Winter C, Berg J, et al. Adiposederived human mesenchymal stem cells induce long-term neurogenic and anti-inflammatory effects and improve cognitive but not motor performance in a rat model of Parkinson's disease. Regen Med. 2015;10(4): 431-46.
23. Choi HS, Kim HJ, Oh JH, Park HG, Ra JC, Chang KA, et al. Therapeutic potentials of human adipose-derived stem cells on the mouse model of Parkinson's disease. Neurobiol Aging. 2015;36(10):2885-92.

24. Berg J, Roch M, Altschuler J, Winter C, Schwerk A, Kurtz A, et al. Human adipose-derived mesenchymal stem cells improve motor functions and are neuroprotective in the 6-hydroxydopamine-rat model for Parkinson's disease when cultured in monolayer cultures but suppress hippocampal neurogenesis and hippocampal memory function when cultured in spheroids. Stem Cell Rev Rep. 2015;11(1):133-49.

25. Takahashi H, Ishikawa H, Tanaka A. Regenerative medicine for Parkinson's disease using differentiated nerve cells derived from human buccal fat pad stem cells. Hum Cell. 2017;30(2):60-71.

26. Cucarián JD, Berrío JP, Rodrigues C, Zancan M, Wink MR, de Oliveira A. Physical exercise and human adipose-derived mesenchymal stem cells ameliorate motor disturbances in a male rat model of Parkinson's disease. J Neurosci Res. 2019;97(9):1095-109.

27. Moayeri A, Darvishi M, Amraei M. Homing of super paramagnetic iron oxide nanoparticles (spions) labeled adipose-derived stem cells by magnetic attraction in a rat model of Parkinson's disease. Int J Nanomedicine. 2020;15: 1297-308.

28. Meligy FY, Elgamal DA, Abd Allah ESH, Idriss NK, Ghandour NM, Bayoumy EMR, et al. Testing alternatives: the use of adipose- derived mesenchymal stem cells to slow neurodegeneration in a rat model of Parkinson's disease. Mol Biol Rep. 2019;46(6):5841-58.

29. Ahmed Hanaa H, Metwally Fateheya M, Aglan Hadeer A, Sayed AH. Exploring potential mechanisms of action of mesenchymal stem cells in parkinson's disease: in vivo study. Int J Curr Pharm Rev Res. 2016;7(5):27582.

30. Zhou Y, Sun M, Li H, Yan M, He Z, Wang W, et al. Recovery of behavioral symptoms in hemi-parkinsonian rhesus monkeys through combined gene and stem cell therapy. Cytotherapy. 2013;15(4):467-80.

31. Chi K, Fu RH, Huang YC, Chen SY, Hsu CJ, Lin SZ, et al. Adipose-derived stem cells stimulated with $n$-butylidenephthalide exhibit therapeutic effects in a mouse model of Parkinson's disease. Cell Transplant. 2018;27(3):456-70.

32. Muñoz MF, Argüelles S, Medina R, Cano M, Ayala A. Adipose-derived stem cells decreased microglia activation and protected dopaminergic loss in rat lipopolysaccharide model. J Cell Physiol. 2019;234(8):13762-72.

33. McKenzie JE, Brennan SE, Ryan RE, Thomson HJ, Johnston RV, Thomas J. Defining the criteria for including studies and how they will be grouped for the synthesis. In: JPT H, Thomas J, Chandler J, Cumpston M, Li T, Page MJ, et al., editors. Cochrane handbook for systematic reviews of interventions; 2019. p. 33-65.

34. Hooijmans CR, Rovers MM, de Vries RB, Leenaars M, Ritskes-Hoitinga M, Langendam MW. SYRCLE's risk of bias tool for animal studies. BMC Med Res Methodol. 2014;14(1):43.

35. DerSimonian R, Laird N. Meta-analysis in clinical trials. Control Clin Trials. 1986;7(3):177-88.

36. Deeks JJ, Higgins JPT, Altman DG. Analysing data and undertaking metaanalyses. In: Higgins JPT, Thomas J, Chandler J, Cumpston M, Li T, Page MJ, et al., editors. Cochrane handbook for systematic reviews of interventions. 2nd ed. Chichester: Wiley; 2019. p. 241-84.

37. Saad MA, El-Sahar AE, Sayed RH, Elbaz EM, Helmy HS, Senousy MA. Venlafaxine mitigates depressive-like behavior in ovariectomized rats by activating the EPO/EPOR/JAK2 signaling pathway and increasing the serum estradiol level. Neurotherapeutics. 2018;16(2):404-15.

38. Carelli S, Giallongo T, Gombalova Z, Rey F, Gorio MCF, Mazza M, et al. Counteracting neuroinflammation in experimental Parkinson's disease favors recovery of function: effects of Er-NPCs administration. J Neuroinflammation. 2018;15(1):333.

39. Damier P, Hirsch EC, Agid Y, Graybiel AM. The substantia nigra of the human brain. II. Patterns of loss of dopamine-containing neurons in Parkinson's disease. Brain. 1999;122(8):1437-48.

40. Ejlerskov P, Hultberg JG, Wang J, Carlsson R, Ambjørn M, Kuss M, et al. Lack of neuronal IFN- $\beta$-IFNAR causes lewy body- and Parkinson's disease-like dementia. Cell. 2015;163(2):324-39.

41. Barker RA, Drouin-Ouellet J, Parmar M. Cell-based therapies for Parkinson disease-past insights and future potential. Nat Rev Neurol. 2015;11(9):492503.

42. Venkatesh K, Sen D. Mesenchymal stem cells as a source of dopaminergic neurons: a potential cell based therapy for Parkinson's disease. Curr Stem Cell Res Ther. 2017;12(4):326-47. 
43. Zuk PA, Zhu M, Mizuno H, Huang J, Futrell JW, Katz AJ, et al. Multilineage cells from human adipose tissue: implications for cell-based therapies. Tissue Eng. 2001;7(2):211-28.

44. Zhou Z, Tian X, Mo B, Xu H, Zhang L, Huang L, et al. Adipose mesenchymal stem cell transplantation alleviates spinal cord injury-induced neuroinflammation partly by suppressing the Jagged $1 /$ notch pathway. Stem Cell Res Ther. 2020;11(1):212

45. Gu W, Nowak WN, Xie Y, Bras AL, Hu Y, Deng J, et al. Single-cell RNAsequencing and metabolomics analyses reveal the contribution of perivascular adipose tissue stem cells to vascular remodeling. Arterioscler Thromb Vasc Biol. 2019:39(10):2049-66.

46. Zhou W, Lin J, Zhao K, Jin K, He Q, Hu Y, et al. Single-cell profiles and clinically useful properties of human mesenchymal stem cells of adipose and bone marrow origin. Am J Sports Med. 2019;47(7):1722-33.

47. Xu H, Li W, Luo S, Yuan J, Hao L. Adipose derived stem cells promote tumor metastasis in breast cancer cells by stem cell factor inhibition of miR20b. Cell Signal. 2019;62:109350.

48. Gentile P, Sterodimas A. Adipose stem cells (ASCs) and stromal vascular fraction (SVF) as a potential therapy in combating (COVID-19)-disease. Aging Dis. 2020;11(3):465-9

49. Kim S, Chang KA, Kim J, Park HG, Ra JC, Kim HS, et al. The preventive and therapeutic effects of intravenous human adipose-derived stem cells in Alzheimer's disease mice. PLoS One. 2012;7(9):e45757.

50. Im W, Ban J, Lim J, Lee M, Lee ST, Chu K, et al. Extracts of adipose derived stem cells slows progression in the R6/2 model of Huntington's disease. PLoS One. 2013;8(4):e59438.

51. Yan Y, Ma T, Gong K, Ao Q, Zhang X, Gong Y. Adipose-derived mesenchymal stem cell transplantation promotes adult neurogenesis in the brains of Alzheimer's disease mice. Neural Regen Res. 2014;9(8):798-805.

52. Zeng XS, Geng WS, Jia JJ. Neurotoxin-induced animal models of Parkinson disease: pathogenic mechanism and assessment. ASN Neuro. 2018;10: 1759091418777438.

53. Koprich JB, Kalia LV, Brotchie JM. Animal models of a-synucleinopathy for Parkinson disease drug development. Nat Rev Neurosci. 2017 Sep;18(9):515-29.

54. Dauer W, Przedborski S. Parkinson's disease: mechanisms and models. Neuron. 2003;39(6):889-909.

55. Schweitzer JS, Song B, Herrington TM, Park TY, Lee N, Ko S, et al. Personalized iPSC-derived dopamine progenitor cells for Parkinson's disease. N Engl J Med. 2020;382(20):1926-32

56. Wang YK, Zhu WW, Wu MH, Wu YH, Liu ZX, Liang LM, et al. Human clinicalgrade parthenogenetic ESC-derived dopaminergic neurons recover locomotive defects of nonhuman primate models of Parkinson's disease. Stem Cell Rep. 2018;11(1):171-82.

57. Kikuchi T, Morizane A, Doi D, Magotani H, Onoe H, Hayashi T, et al. Human iPS cell-derived dopaminergic neurons function in a primate Parkinson's disease model. Nature. 2017;548(7669):592-6.

Ready to submit your research? Choose BMC and benefit from:

- fast, convenient online submission

- thorough peer review by experienced researchers in your field

- rapid publication on acceptance

- support for research data, including large and complex data types

- gold Open Access which fosters wider collaboration and increased citations

- maximum visibility for your research: over $100 \mathrm{M}$ website views per year

At BMC, research is always in progress.

Learn more biomedcentral.com/submissions 